\title{
A Study of Chinese Culture Aphasia in College English Teaching in China*
}

\author{
Jie Song \\ School of Foreign Languages, Shanxi Normal University, Linfen, China \\ Lin Bai \\ Shanxi Normal University, Linfen, China
}

\begin{abstract}
The relationship between language and culture make culture teaching enter into FLE that cultural understanding of the target language is indispensable. But much emphasis on western culture led to Chinese culture aphasia among Chinese English learners. Consequently, an investigation is conducted in this paper to check whether the phenomenon exists; and if so, to test the extent, reasons and feasible solutions of students' aphasia of Chinese culture. The results demonstrate the tested college students master the Chinese culture well, but have difficulties in translating them into English and some college English teachers are not proficient in translating sentences containing Chinese culture into English. Chinese Culture Aphasia is due mainly to lacking of Chinese culture in college English teaching class. Based on analyzing results of the investigation and summarizing scholars' teaching strategies, the author claims the incorporation of Chinese culture into college English teaching adhering to certain principles, effective teaching strategies including preparing reasonable syllabus and improving teachers' comprehensive qualities.
\end{abstract}

Index Terms - native culture, Chinese Culture Aphasia (CCA), culture teaching, college English teaching (CET)

\section{INTRODUCTION}

\section{A. Background of the Research}

Along with the international process deepening, English has become the well-known world language. In the 21st century, with the feature of diversity and internationalization, English plays a more active role in the exchange of various languages. With the development of the theories of linguistics, language teaching is becoming more and more mature, from teaching the language itself to teaching the culture related to it. Learning foreign language means coming into contact with a kind of new culture. The interrelated relationship between language and culture makes culture teaching an important part in foreign language education. Along with the development of China's reform and opening-up, Chinese people, especially the young men, are crazy about English learning, Western festivals and new things. The Chinese Culture Aphasia, namely, in capability to express Chinese culture in any language but the native language can be found everywhere. The phenomenon of Chinese culture aphasia has been concerned about by the foreign language educators for several years, but it has not yet been meliorated effectively.

In the field of foreign language teaching, researchers and scholars focus on the importance of cultural awareness of target language and it proves successful in increasing Chinese students' cross-cultural communicative competence to some extent. However, Chinese culture tends to be ignored in English teaching in China. Due to the inequality between Chinese and English cultures in English language teaching, Chinese learners of English have some difficulties when they are talking about things which are specific to Chinese culture although they have a good command of English and English culture. As is known, communication is a two-way activity. It would not make sense when one side can not provide information new to its counterpart. Cultivating Chinese English learners' correct cultural awareness in intercultural communication and improving their ability to express Chinese culture-specific items in appropriate English expressions and spread Chinese traditional culture to the world is the effective way to solve the problem of Chinese culture aphasia.

\section{B. Purpose of the Research}

English globalization brings about English localization all over the world. Various English variants appear, such as India English, Australia English, Singapore English and so on. In that situation, English has never belonged to certain nation so that the culture it reflects has not only been the culture of English-speaking countries but the world culture. However, Western countries rely on its strong comprehensive strength to carry out the cultural infiltration to the Third World, but the people there can't establish the cultural identity to their own culture.

\footnotetext{
* This work was supported by the Project of Philosophy and Social Science Research in Colleges and Universities in Shanxi Province (Grant No. 2013227).
} 
In China, English has never had such great influence in China since the Open Policy was adopted in 1978. It seems there are more people learning to speak English in China than the English native speakers in the whole world. Nobody can deny that English has grown closer and closer to the daily life of the Chinese people. However, with the number of English learners increasing, it seems to be difficult to find translation personnel of high quality. Experts pointed out that the ignorance of native culture teaching in FLT led to the deficiency of high level translators. The Chinese Culture Aphasia, namely, incapability to express Chinese culture in other language except the native language can be found everywhere. So putting emphasis on the learning of Chinese culture and its expressiveness is to meet the need for cultural equality and mutual understanding. It is well-known that language teaching and cultural teaching cannot be separated. Since the mid-20th century, the studies on foreign language teaching aboard and in China have started to search for the effective teaching approaches to satisfy the continuously changeable communicative needs after throwing off the traditional Grammar-Translation Method. The effect of the two sides' cultural background in cross-cultural communication attracted the concern. Since expressiveness of Chinese culture is so important for Chinese EFL learners, especially college students, so what are their attitudes towards Chinese culture and can they transmit Chinese culture freely and accurately when they talk to foreigners. The purpose of this investigation is to undertake a comprehensive and thorough scrutiny into college students' expressiveness of Chinese culture in English, which aims at revealing whether aphasia of Chinese culture exists among college students. After the investigation, I will try to find the reasons of the phenomenon which may be helpful for English teachers in their further researches.

\section{Significance of the Research}

It has still been a very important question that what should be taught in foreign language teaching (FLT). The assumable answer to this question rests on how we understand the aim of second language learning and teaching. In the last century, the teaching target of foreign languages has been extended from language skills to communicative competence, and then to intercultural communication. In China, since the open-door policy, cultural teaching has been receiving more and more attention. It has been commonly accepted that culture teaching should be laid emphasis on in the process of English teaching. Correspondingly, a large number of scholars have made systematic researches in the objectives, principles, content and methods of culture teaching, which contributes a lot to the development of culture teaching. However, the achievement is mainly reflected by the target culture teaching. In fact, the students can not express Chinese culture in appropriate English, which causes the phenomenon of Chinese culture aphasia in intercultural communication. This phenomenon is undoubtedly due to emphasizing too much of the target culture while ignoring the input of the Chinese culture. Since intercultural communication is a kind of two-way activity and this feature determines that the emphasis should also be included in culture teaching. English learning should not learn the target culture only but understand native culture better and then introduce Chinese culture to foreigners by using English. Otherwise, it will certainly bring about obstacles in communication, let alone the realization of effective inters cultural communication.

This thesis will attempt to, firstly, reveals the necessity of teaching Chinese culture to Chinese students in college ELT; and secondly, arouse Chinese people's cultural awareness and cultural confidence in their English learning; and finally some pedagogical implications will be derived from the analysis and research work.

The author looks forward to displaying the present situation that the phenomenon Chinese Culture Aphasia exists to attract numerous educators' concern.

\section{Organization of the Thesis}

Chapter 1 is the introduction of this study. In Chapter 2, the author retrospects the brilliant achievements of foreign language educations and the development process of cultural teaching at home and aboard since 20th century. The relevant studies on Chinese Culture Aphasia in China are briefly introduced. Chapter 3 offers the relevant theories on the study of Chinese Culture Aphasia in Chinese universities, such as among non-English majors, English majors and English teachers. Chapter 4 introduces the principles, the teaching contents and the concrete approaches of incorporating Chinese culture into English teaching. In Chapter 5, the author gives this study a conclusion.

\section{LITERATURE REVIEW}

\section{A. A Review of Researches on Cultural Teaching}

This part introduces the researches on cultural teaching abroad and in China. In foreign language education, the importance of teaching foreign culture has been widely recognized. A lot of researches have been done and much progress has been made both at home and abroad. From that, we can obtain the information on the differences between Chinese and Western cultural teaching in foreign language teaching.

1. A review of researches on cultural teaching abroad

Even in the West where language-teaching theories have always set the pace, culture teaching has a history of only a century or so. As far as the language teaching in the western countries, culture teaching has been connected closely with language teaching ever since Latin teaching in the Middle Ages. The recognition of the importance of teaching culture in foreign language education can be traced back to the late nineteenth century. Byram proposed the necessary of cultural studies in foreign language education in 1989. There was "no reference to anything that might be described as 
the cultural 'aspect of language teaching"' (Stern, 1999). Brown (2002) concentrated on the exploring and summarizing the principles of language learning and teaching. The Art of Teaching and Studying: Languages by Gouin (2012) pointed out the importance of culture teaching for the first time, but did not receive support on a large scale. One year later, The Report of the Committee of Twelve of the Modern Language Association of America officially acknowledged the teaching of European civilization and recommended it for school curricula. The breakout of the First World War caused the increasing concern for the understanding of and the difference between cultures of all nationalities, hence the reform of foreign language teaching through adding culture teaching to language teaching. The Second World War made more necessary than ever before the training of people mastering both the foreign language and its culture related. At that time, Area Studies, a new subject, was introduced into some US universities. Under the influence of Area Studies, foreign language teaching became more and more cross-disciplinary instead of being isolated from other subjects. In 1959, Hall put forward an amplified modification known as the Ten Primary Messages System, which identifies ten focal points of critical importance to the fabric of society. In Hall's proposition, the scope of culture in language education has been expanded from " $\mathrm{C}$ " to " $\mathrm{c}$ ". Generally speaking, the main characteristics of culture teaching in that period are as the followings: Firstly, no matter what models are suggested or used, content about foreign cultures is explicitly provided. Secondly, the explicit knowledge about foreign culture is expanded from "C" to "c". In general, scholars realized that foreign language and its relative culture should be combined in foreign language education after the continuous studies in this period.

On the basis of the preceding study on the incorporation of culture into foreign language education, the appearance of communicative language teaching method has pushed it to advance since the late 1960s. In Wilkins' famous Notional Syllabus Revisited: a Further Reply (1981), he suggested introducing culture to language teaching. Only as language was connected with certain culture, it could be endowed with certain meaning. That is to say, culture and language should become a unity, which are no longer independent and isolated from each other. Hymes (1979) proposed the concept of communicative competence, which was a supplement to the concept of linguistic competence raised by Chomsky. In his opinion, besides linguistic competence, communicative competence should include the full understanding and a good command of the socio cultural elements closely related to the language use. In terms of Hymes' point, four questions must be emphasized if linguistic theory is to be integrated with theory of communication and culture as follows:

(1)Whether (and to what degree) something is formally possible;

(2)Whether (and to what degree) something is feasible in virtue of the means of implementation available;

(3)Whether (and to what degree) something is appropriate (adequate, happy, successful) in relation to a context in which it is used and evaluated;

(4)Whether (and to what degree) something is in fact done, actually performed, and what its doing entails.

With the rapid economic development and scientific progress in the West, a large amount of overseas students prefer to study in English-speaking countries. That has promoted the emergence of a new discipline known as inter-cultural communication since the late 1970s. As a result, the teaching of foreign culture in language program has been influenced by this discipline, which challenged the traditional approaches either adding culture background knowledge to the teaching of language skills or seemingly integrating culture behavior with language learning by the students themselves. In the following years, a large number of publications have appeared. The researches into inter-cultural communication have supported the teaching of foreign language and culture. Rohrlich's trifocal approach (1983) enabled us to examine the process of intercultural communication in a comprehensive manner. According to Rohrlich, "the study of intercultural communication must involve three levels. The first level is the intra-personal level". The second one is the interpersonal level. The third one is the synthetic level. Many theoretical ideas and researches have had a great impact on foreign language education. The proposition of teaching native culture in the culture teaching of FLT came into being and gradually obtained attention from growing numbers. English is used not only to know foreign culture, but also to make the learner's own culture understandable to foreigners. So learners should be required to have a better understanding of both foreign culture and home culture.

2. A review of researches on cultural teaching in China

Compared with Western cultural teaching, it is obvious that China has lagged behind in foreign language education. Similar to FLT in western countries, China's FLT has also witnessed the over-emphasis on the imparting of pronunciation, vocabulary and grammar and the training of basic skills of listening, speaking, reading and writing. With China's policy of opening up to the world and the increasing economic contacts with other countries, language educators and scholars became aware that one could not communicate smoothly with native speakers unless he was well equipped with target culture. $\mathrm{Hu}$ is commonly regarded as one of the pioneers who advocated culture teaching in foreign language education. He suggested in 1999 that foreign language teachers should keep a close eye on the development of anthropology and sociology, and consciously integrate them in FLT. Culture teaching in this period is only regarded as the introduction of culture elements in FLT, whereas the research is neither systematic nor mature. During this period one thing noticeable in foreign language education is the introduction of intercultural communication focusing on communicative skill in practical situations, which has exerted deep influence on culture teaching in FLT. Thus out came a large number of publications. Gu and $\mathrm{Lu}$ (2005) expanded the relationship between language and culture from macro aspects, at the same time, presented the characteristics of various foreign cultures from micro 
aspects, such as ethnic cultural values, traditions, literatures and so on. Scholars have realized the importance of values, social norms, and ways of life as well as that of material culture. Culture teaching since late 1990s till now is the period of reflection and improvement. Many scholars have realized the problems existing in cultural teaching of Chinese foreign language teaching and put forward various methods to solve those problems. Cong (2000) first put forward the concept of aphasia of Chinese culture, which attracted language educators' attention. Chen \& Du (2008) stated Chinese Culture cannot be neglected in English specialized teaching process.

In a word, from the general review of 100 years' culture teaching in China, we can see that great improvements have been achieved.

\section{B. A Review of Researches on Chinese Culture Aphasia}

The term aphasia, often used as the disease in medical science, is called dysphasia abiding by what explained in Encyclopedia Britannica of 1984, referring to brain-generated defect in sounding words. Symptoms are associated with the location and extent of involved brain tissues. An afflicted person, for example, although able to move his mouth parts and utter words and able to understand spoken words, may be totally unable to form words himself. Another aphasic person may be able to say the word hopper but be unable to say the word hop. An article named "Aphasia of Chinese Culture: a Flaw in FLT in China"(Cong, 2000)was published in Guangming Daily on October 19, 2000.The author of this article Cong, from Nanjing University, referred to the term of "Aphasia of Chinese Culture" for the first time. He claimed that China's language researchers have realized the significance of cultural teaching, but only referring to the material cultures, Institutions and customs as well as various dimensions of spiritual culture from English-speaking countries. However, the cultural background of the other side in cross-cultural communication--Chinese culture, was neglected. In his opinion, the expression of Chinese culture in English should be incorporated into all levels of English teaching in order to cultivate students' cultural subjectivity and integrity. It wasn't until Cong's advent that people came to realize the urgency of incorporating native culture in FLT, thus came out a lot of writings on its necessity and a series of investigations on "Chinese Culture Aphasia".

\section{The CAuse of Chinese Cultural Aphasia}

\section{A. English Craze}

With the policy of opening up kept going on and international communication considered more important than ever before, there are more and more people learning English and English has exerted its overwhelming influence on entering into college, passing the exam of graduates and professorship and hunting for jobs and so on.

International communication is more than ever before and English has become one of the most important international languages. So it is necessary to learn English. But it seems that English learning has deviated from the track of popularity and neglected its original objective and intention which requires nearly everyone to learn English, whether he or she is a driver or just a shop assistant in the supermarket.

There are some negative results of English Craze in the circle of nearly every walks: (1) the waste of teaching resource. In our country the teaching resource is very limited so that when more teaching resource is used on English learning, there must be less for the learning of other kinds of knowledge which are also requisite for students' development. (2) a waste of intellects. There are people who are competent in learning languages and some not, who, however, are encouraged and sometimes are forced to learn English to follow the tide of popularizing English. (3) Most important of all is that English learning at present has affected students' mastery of Chinese culture which is of vital importance for cultural identity of one nationality. English learning has taken students so much time and energy that they cannot spare time to enhance their understanding of Chinese culture and nurture their interest in it and their sense of cultural identity. Too much time spent on English learning has interfered strongly with their studying the subjects concerning their majors because if they cannot pass CET-4, in many universities it is very possible that obtaining their diplomas is totally out of question. Under that pressure, they are unable to spare time to enhance their quality in Chinese culture, let alone English expressions of Chinese culture. Therefore, students are more easily influenced by foreign cultures. They even cannot distinguish the right from the wrong in foreign cultures because they always hold the view that foreign are right. The affection for Chinese culture nearly disappears in their mind where Chinese culture does not have a position that it should have. Unfortunately, they have not enough accumulation of the essence of Chinese culture.

\section{B. The Absence of Chinese Culture Courses in Curriculum Design}

In china, English teaching syllabus at each stage has the supreme authority on curriculum development, textbook compilation, testing and assessment, while all of those elements exert great influence on every aspect of English teaching and learning. To some extent, it determines where we go teaching objective, what to teach teaching content and how to teach teaching approaches. As the embodiment of the cultivation objectives, curriculum design is based on teaching syllabus. According to the syllabus, the cultural courses in ELT is not only to provide students with information about foreign countries, but also to improve their cultural sensitivity, tolerance, and flexibility to deal with cultural differences, to train them to absorb the quintessence of word culture critically and spread Chinese traditional courses, to train their thinking ability and creativity. In China, curriculum of EFL teaching is usually prescribed by the Ministry of Education. The present curriculum design for Chinese Students in College pays little attention on Chinese 
culture, which, to some extent, results in the English majors' "Chinese Culture Aphasia".

\section{English Teachers}

From the analysis of the former investigation, the author think that the ubiquitous phenomenon Chinese Culture Aphasia on college students is not only caused by their own ignorance of studying Chinese culture, but also directly related to the educators. Culture has been considered as an inseparable part of foreign language education. However, in the field of EFL, culture teaching isn't mature enough to avoid problems among which the most serious one is that foreign language teachers and researchers have misunderstood the content of culture teaching and paid most of their attention to target culture (Western culture), but ignored learners' home culture (Chinese culture). No matter in the researches on culture teaching or in teaching practice, the ignorance of home culture is obvious and severe. Strong culture attacks weak culture along with advanced culture obstructing backward culture. That is the inevitable result of cultural choice. Modern Western culture, together with Western political power, military and economic hegemony has obtained the world's cultural authority. That is the enormous external pressure to cause Chinese Culture Aphasia. Lack of clear understanding, equal and peaceful mind, incapability to think about cultural teaching in foreign language education from the standpoint of safeguarding national culture as well as failing to face the challenges of Western dominant culture with strong national self-esteem and self-confidence are the underlying causes of Chinese Culture Aphasia. That is worth serious consideration to educators.

\section{Methodology}

\section{A. The Necessity of Teaching Chinese Culture to Chinese Students in College ELT}

As we know, communication is a kind of reciprocal and two-way activity. In an intercultural communication context, Chinese Foreign language learners are expected to be the "ambassador" of Chinese culture. Chinese college students have the obligation of applying English to introduce Chinese culture to foreign friends who cannot speak Chinese. However, what embarrasses the students is their inability in expressing Chinese culture related topics and matters related to their own traditions and lives, which the foreigners are most interested in. There are two important factors explaining this phenomenon: the students know little about their native culture and can't express them in English. The phenomenon resulted from the latter factor is called "Chinese culture aphasia", first cited by Cong in 2000. After more than ten years of English learning, when communicating with foreigners, many students still can't give some simplest expressions on native culture in English, let alone develop their intercultural communicative competence. The status quo of culture teaching in college ELT partly explains the two factors. For Chinese students, the native culture has been neglected in ELT because of the overemphasis on Anglo-American culture. Chinese students gradually lose their interests in studying native culture because of the current situation of western-centric culture teaching in college ELT. The privilege of western culture will result in the wrong viewpoint that knowledge on Chinese culture is useless for international communications. However Chinese culture is indispensable in ELT because it can be an important resource for Chinese learning English and developing intercultural communication competence. If a large amount of Chinese college students acquire the ability of expressing Chinese culture in English, their English language competence will be improved and the internationalization of Chinese culture will be promoted.

\section{B. The Methods to Solve the Phenomenon}

From the previous chapters, it seems that although scholars and educators have realized the important role of home culture in foreign language education and the cause of the Chinese Culture Aphasia. Therefore, an investigation is conducted to explore the current situation of culture teaching for college students, discover the problems involved in it and seek out the feasible solutions.

1. To prepare the reasonable syllabus

Syllabus refers to the teaching guidelines, including the purpose and task of teaching, the scope, depth and structure of teaching contents, teaching progress as well as the basic requirement of teaching methods and so on. In China, English teaching syllabus plays a dominant role in textbook compilation, curriculum design, testing and assessment, and exerts great influence on every aspect of English teaching and learning. Up to now, college English teaching syllabus issued by the Ministry of Education has undergone three significant changes. The fundamental goal of English teaching is to train students' cross-cultural communicative competence, namely, communicate with people from various countries and regions smoothly. In order to adapt to the new situation of higher education and upgrade the overall language teaching quality, The Requirements of College English Teaching is issued at the beginning of 2004 . It specifies the teaching objective as: to train students' comprehensive competence of using English, especially their listening and speaking abilities so as to satisfy their needs of communication in their future career in an oral or written way. In relation to the speaking ability in the common requirements of syllabus, it says that students should be able to communicate with foreigners in English to discuss some daily-life topics and make small talks concerning a familiar topic with the use of some basic strategies of making dialogues. Although successful communication requires students' familiarity with Chinese culture and competence for expressing it in English, yet there is still no clear regulation setting Chinese culture holds basic and necessary position. The contents of cultural teaching in college English teaching should include broad culture and narrow culture, home culture and target culture, mainstream and non-mainstream culture. In 
classroom teaching, teachers ought to combine language teaching with cultural teaching with various teaching tools actively to offer students the imitated communication scenario to help them consolidate knowledge and improve communicative competence in practice. According to the concrete teaching needs, teachers should use the appropriate teaching approaches. To increase the proportion of Chinese culture in college English teaching, the testing contents and methods ought to be regulated accordingly.

2. To improve teachers' comprehensive quality

As the executor of foreign language teaching, English teachers' knowledge and accomplishment, to some extent, determines the teaching effect and development of students' cross-cultural communicative competence. English teachers should first establish a firm cultural standpoint, realize the values of Chinese culture and its unique contribution to the mankind's cultural development as well as the significance of learning home culture is to deepen the understanding of foreign culture, improve learners' ability to identify and appreciate foreign cultures. In view of the shortcomings of current textbook, English teachers should not be confined to reading only Western materials, but should come into contact with English reading materials and newspapers about Chinese history, nationality, politics and technology. Meanwhile, the cross-cultural communicative awareness will contribute to the deep understanding of the differences between Chinese and Western culture together with how to deal with the cultural conflicts gracefully under respective backgrounds. English teachers ought to use correct cultural teaching approaches to imitate the possible conflict scenarios between Chinese and Western culture in classroom teaching, guide students to set up the equal cultural communicative awareness, tolerance and capability to deal with the cultural conflicts.

3. Summary

Nowadays, college students can master the Chinese culture well, but their capacity of expressing Chinese culture in English is weak. However, English teachers should also focus on the accumulation of Chinese cultural vocabularies. College English teaching's lack of the contents of Chinese culture and neglect of the teaching of English expression of that is the main cause of the phenomenon Chinese Culture Aphasia. In spite of that, both college students and English teachers hold the faith and hope to search for the effective methods to overcome Chinese Culture Aphasia together through their respective efforts. The author looks forward to displaying the present situation that the phenomenon Chinese Culture Aphasia exists to attract numerous educators' concern and listing the practical teaching approaches to make a little contribution to overcoming the phenomenon Chinese Culture Aphasia.

\section{CONCLUSION}

\section{A. Limitations of My Research}

The results of the empirical study indicate that students are unqualified to export Chinese culture. To dig out the underlying reasons for such phenomenon, a close examination on such constitutes like English Teaching Syllabus for Chinese Students in College, curriculum design, textbook for Comprehensive English have been analyzed. The analysis indicates that the marginalization of Chinese Culture in EFT is mainly attributed to Chinese Students in College Chinese Culture Aphasia, reflected by the following 3 aspects: (1)the ambiguous description of cultural teaching requirements in teaching syllabus; (2)the absence of Chinese Culture courses in curriculum design; (3)the neglecting of Chinese Culture in textbooks. The author expects those findings will arouse the sensitivity of Chinese foreign language education administrator, textbook composer, language teachers and learners to the significance of Chinese culture in EFT. What's more, it raises the awareness to make improvement and adjustment in current English teaching. Nevertheless, the job I have done in this thesis can hardly be more than tentative, owing to the restricted time, especially my limited knowledge. The study solely focus on the teaching syllabus, courses provision and textbooks, which makes the analysis far from comprehensive, as we know, language instruction involves many components, like students, teachers, materials, teaching methods and evaluation. The thesis only involves part of the material, though it often controls the instruction.

\section{B. Further Studies of My Research}

With English becoming more and more popular and pervasive, the discussions about how to teach English are, accordingly, getting more heated than ever before, hence pushing forward the development of culture teaching. The present study is an initial attempt to construct conceptual frameworks and instructional models of Chinese culture teaching in college ELT for Chinese and international students. The main purpose of this thesis is to draw foreign language educators and teachers' attention to the integration of home culture in English teaching for Chinese Students in College, thus promoting the cultivation of students' cross-cultural communicative competence and the improvement of their all-round quality. Therefore, it has a practical significance. However, there are some limitations in the thesis. The present study only investigates Chinese Students in College mastery of Chinese culture and expressive of Chinese culture in English. The study suggests incorporating Chinese culture and diversifying target culture in teaching materials. However, as to which aspects of culture and how many proportions each culture shares need further investigation and discussion. This study solely probes the trouble that lies in expressiveness of Chinese Students' Chinese culture in English and some factors leading to their inferiority in this ability. Further research is expected to explore specific teaching methods, activities and strategies to cultivate learners' ability to present Chinese culture in English. 


\section{REFERENCES}

[1] Brown, H. D. (2002). Principles of Language Learning and Teaching. Beijing: Foreign Language Teaching and Research Press.

[2] Byram, M. (1989). Cultural Studies in Foreign Language Education. Clevedon: Multilingual Matters.

[3] Chen, J. P. \& Du, J. (2008). A Non-negligible Class in English Specialized Teaching: Chinese Culture. Journal of Chengdu University (Educational Science Edition), 7, 56-57.

[4] Cheng, S. J. (2011). A Research of Chinese Culture Aphasia on English Majored Undergraduates. XianYang: Northwest A\&F University.

[5] Cong, C. (2000). Chinese Culture Aphasia: Defect in Chinese English Teaching. Guang Ming Daily, 10(19), 2-3.

[6] Gouin, F. (2012). The Art of Teaching and Studying: Languages. London: Forgotten Books.

[7] Gu, J. Z. \& Lu, S. (2005). Language and Culture. Shanghai: Shanghai Foreign Language Education Press.

[8] Hall, E. T. (1959). The Silent language [M]. New York: Doubleday.

[9] Hu, W. Z. (1999). Aspects of Cross-cultural Communication. Beijing: Foreign Language Teaching and Research.

[10] Hymes, D. H. (1979). On Communicative Competence. Philadelphia: University of Pennsylvania Press, 65.

[11] Rohrlich, P. E. (1983). Toward a Unified Conception of Intercultural Communication: An Integrated Systems Approach. International Journal of Intercultural Relations, 7(2), 191-209.

[12] Stern, H.G. (1999). Fundamental Concepts of Language Teaching. . Shanghai: Shanghai Foreign Language Education Press. 263.

[13] Wilkins, D. A. (1981). Notional Syllabus Revisited: a Further Reply. Applied Linguistics, 2(1), 83-89.

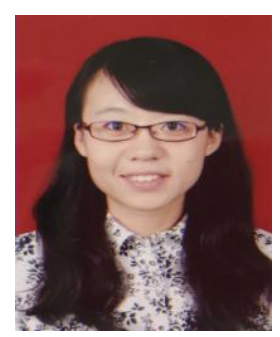

Jie Song was born in Linfen, China in 1982. She is an associate professor in the School of Foreign Languages at Shanxi Normal University in China. She received her B.A. degree in English Education and her M.A. degree in Foreign Linguistics and Applied Linguistics from the School of Foreign Languages at Shanxi Normal University in 2003 and 2008 respectively.

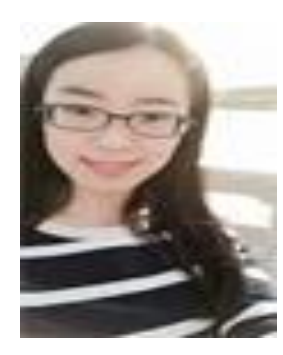

Lin Bai was born in Lvliang, China in 1991. She is a postgraduate student in the School of Foreign Languages at Shanxi Normal University in China. She received her B.A. degree in English from Modern College of Science and Arts, Shanxi Normal University in 2014. 